\title{
Relevance of Counselling Services among Graduate Students at Kwame Nkrumah University of Science and Technology, (KNUST), Kumasi, Ghana
}

\author{
Victoria De-Graft Adjei ${ }^{1}$, Regina Nuako ${ }^{2}$ and Bernice Ofosuhene S. Peasah ${ }^{1}$ \\ ${ }^{1}$ Counselling Center, Kwame Nkrumah University of Science and Technology \\ ${ }^{2}$ General Administration, Kwame Nkrumah University of Science and Technology
}

${ }^{1}$ Correspondence: vdadjei.reg@,knust.edu.gh

\begin{abstract}
This is a study showcasing the utilization and knowledge of Counselling Services by Graduate Students at KNUST. The counselling Center of KNUST has been in existence over a decade and most of the clients that patronize its services are undergraduate students with few being Graduate Students. This paper was basically aimed at examining the level of awareness the KNUST Counselling Center, the services provided for members of the university community including graduate students and patronage of the services among Graduate students. There is minimal literature about studies done on Graduate students and counselling and there has not been such study to examine the impact of counselling among Graduate students in a university in Ghana. Therefore, it is hoped that this study will lead to further studies among graduate students towards better ways of resolving their issues to improve their mental health. From the study, most Graduate students attest to the fact that Counselling is very important and some confirmed that they would recommend the KNUST-Counselling Center to other students. The services and benefits of the KNUST Counselling Center are described in this paper. Alternative ways for effective utilization of the services of the counselling center are explained to support graduate students to improve their mental heal while in school.
\end{abstract}

Keywords: counselling services, relevance, graduate students, KNUST

Citation: De-Graft Adjei, V., Nuako, R. and Peasah, B. O. S. (2021). Relevance of Counselling Services among Graduate Students at Kwame Nkrumah University of Science and Technology, (KNUST), Kumasi, Ghana. International Journal of Technology and Management Research (IJTMR), Vol. 6 (2): Pp.81-86.

Received: April 19, 2020

Accepted: September 1, 2021 


\subsection{Introduction}

KNUST, a member of the international association of universities (IAU), is committed to attracting and developing excellent staff and students in order to contribute towards the achievement of the goals, targets and directions that the government has set for Higher Education through its core values; leadership in innovation and technology, culture of excellence, diversity and equal opportunity for and integrity and stewardship of resources (KNUST, Vision 2020-2024). Again, the mission of KNUST is to advance knowledge in science and technology through creating an enabling environment for undertaking relevant research, quality teaching, entrepreneurship training and community engagement to improve the quality of life. Thus, avenue for graduate and postgraduate studies is very critical for the mission of KNUST to be realized. Graduate and postgraduate studies come with many challenges that make students emotionally unstable and which in turn affect the quality of their experience and studies on campus (Fox \& Butler, 2007). Given the significant attrition rates for higher by degree research students (Evans, Evans, \& Marsh, n.d.), a solid argument could be made for timely provision of more effective psychological care and emotional mentoring for higher by degree research students (Mark Pearson, 2012). Such emotional instabilities have the potential of affecting the performance of students and also leaving a lasting negative impression on students about the institution.

Whether students know about the availability of counselling services in a school or not is a major determinant of how well they access or do not access them. Fox and Butler (2007) found that some students' problem with school counselling services was that it was not widely known. Orientation programmes are organized every year for all firstyear students to brief them on the services available at KNUST. Participation at these orientation programmes is mainly from the undergraduate students. Most graduate students do not attend probably because they think that they have outgrown such programmes. It is very important that graduate students are made aware of the offices/departments that provide welfare services in order that they would assess such services when the need arises because Publicity is a major blockade to access to counselling services. The KNUST Counselling Center (KCC) is very critical in providing emotional and psychological services to the university community especially graduate students.

The KCC is a mental health facility dedicated to the promotion of a healthy environment for students, staff and their dependents as well as the general public. The KCC shares the belief that good mental health is pivotal to personal, academic, and career success. The vision of KCC is to provide high quality mental health support services to students, staff and the general public. Thus, the KCC seeks to support the mission of KNUST in creating an enabling environment for undertaking relevant research, quality teaching, entrepreneurship training and community engagement to improve the quality of life.

The KCC offers many services that will be beneficial to Graduate Students; Individual Counselling/Therapy, Couple/Family Therapy, Crisis Management Counselling, Training Programs, Psycho-educational seminars/workshops and Career counseling and the provision of Psychological Assessments. These services are available to all in a professional manner, as is a principle of Counselling, to wit, Counselling is for all ages and continuous in nature. 
Counsellors encourage self-care and wellness to enhance mental health. This is done directly with individual students in a confidential manner and through on-campus programming. It can help increase self-confidence, improve relationships, achieve educational goals, and make good decisions for emotional, intellectual, physical, and spiritual well-being. Most people, at one time or another can benefit from counselling through which they are motivated to complete their research. Pitchforth et al., (2012), stipulated that Motivational factor is considered a new factor which has been studied in the context of determining factors contributing to the timely completion of $\mathrm{PhD}$. Positive emotional state, continuity of study and personal circumstances are among the aspects included in the study of motivational factor.

It is very easy to become overwhelmed by various academic and social pressures (finance, work, family and health related issues) during graduate studies, especially if one isolates him/herself from potential sources of support. There are sources of support for graduate students of KNUST especially the support services from the KCC for graduate students who feel like they are struggling. The first step towards overcoming such struggles is when one is made aware of such services. However, many graduate students do not see the importance of Counselling in their lives. Some see themselves mature to handle their problems when in fact they seem overwhelmed. Yet others have misconception about counselling, to wit, think counselling is for only the young and immature people. They see counselling as a service for the weak.

Many graduate students are suffering in silence because they do not want their colleagues to see them as weak. This has led to a large number of them struggling to finish their programme, and others also abandoning their studies. Yet, there are others who defer their programmes with the intention of solving their problem before they continue school and who get overwhelmed (with their problems) and eventually abandon the programme.

\subsection{Methodology}

The study was qualitative and a descriptive survey was used. The survey was conducted to assess the level of awareness of the existence of the KCC and patronage of its services among graduate students of KNUST. Sarantakos (1998) intimates that descriptive research is describes a phenomenon and is able to make generalizations concerning a larger group where a sample was drawn. According to Amedahe (2003) in descriptive research, accurate description of activities, objects, processes and persons is objective. The study was conducted at KNUST and it was targeted at graduate and postgraduate students. A purposive sampling was used to reach out to all graduate and postgraduate students through structured questionnaire on google form. The questionnaires were sent to all graduate and postgraduate students (1251) and a total of 162 students participated in the study in completing the questionnaires.

\subsection{Results}

Out of the total of 162 graduate and postgraduate students who participated in the study, 105 (64.8\%) were females and $57(35.2 \%)$ males. Although, $125(77.2 \%)$ responded that, they were aware of the existence of the KNUST Counselling Center (KCC). As many as 154 (95.3\%) of the participants responded that, they have never been to the KCC. Again, only 8 (4.7\%) have at one point or another visited the KCC to seek assistance with regards to academic, relationship and self-esteem issues; and $93.7 \%$ of them responded that, they have never patronized the services of the KCC. 


\subsection{Benefits of Counselling to Graduate Students}

Makinde, (2000) posits that counselling is a service designed to help individuals analyse their capabilities, achievements and interests and mode of adjustment toward new decisions he has made or have to make. Counselling services and programmes help students resolve emotional, social or behavioral problems and help them develop a clearer focus or sense of direction. Effective counseling programmes are important to the school climate and a crucial element in improving student achievement.

The KCC shares the belief that good mental health is pivotal to personal, academic, and career success. This is in line with the view of Ipaye, (2000), who states that counselling helps the individual to utilize his/her psychological resources by looking at his strengths for development and concentrating on his/her personality, behavioural and emotional assets. Therefore, its vision is to provide high quality mental health support services to students, staff and the general public. The Center has well trained and professional Counsellors and Clinical Psychologists who provide emotionally safe, respectful, confidential, and compassionate counselling services that facilitate development and greater subjective wellbeing of clients. KCC is accredited with the Ghana Psychological Council (GPC) and all Staff are individually accredited with GPC.

The services provided by the KCC include the following:

- Individual Counselling/Therapy

- Couple/Family Therapy

- Crisis Management

- Counseling Training Programs

- Psycho-educational seminars/workshops

- Career counselling

- Provision of Psychological Assessments (e.g. Intelligence Tests, Personality Tests, Neuropsychological/Memory Tests)

- Substance Abuse (drug, alcohol use etc.)

- Annual Counselling and Emotional Health Awareness Week that includes a health screening exercise

- Support for persons with Disability

The KCC engage in periodic research to inform and enhance practice. All sessions with clients are strictly confidential and private.

The goal of counselling is to seek lasting change in the individual. Garry (2007) states that more often, people seek counselling to resolve marriage problems, crisis, depression, interpersonal conflicts and anxiety. Postgraduate students stand to benefit greatly from the services of the KCC in the following areas:

- Clarifying problems

- Reducing/Coping with stress/depression

- Developing increased confidence

- Exploring opportunities for change

- Improving personal/ interpersonal skills 
- Learning to make better decisions

- Managing anxiety

- Managing family, work and school.

\subsection{Conclusion}

Through Counselling comes the development of insight and increased self-awareness. People are able to gain a better understanding of their own behaviour and the issues, feelings and events that motivate them. The most useful benefit of therapy is often an improvement in mental health and total well-being. This often translates into increased selfconfidence, productivity and a greater sense of vitality and peace of mind. People of any age can grow and profit from the experience of therapy. Some postgraduate students are suffering emotionally and academically and either feel shy to talk about it or do not know where to seek help from. There is no "wrong" time to begin; the time is now.

\subsection{Recommendation}

A few postgraduate students who responded to referrals to the KCC have benefitted and averted situations which would have pushed them out of school. It is high time the Executive of the Graduate Students' Association and the administration of the School of Graduate Studies teamed up with the KCC to make counselling services visible to the graduate and post graduate students. The following are recommended:

\section{Online/phone/E-Counselling for graduate students}

Since IDL uses the Virtual Classroom (Vclass) in teaching, some IT personnel could be hired to develop an App for IDL students to access counselling services online (Phone/Cyber/Virtual Counselling). Thus, the coordinators trained as skilled helpers could provide counselling support online with support from the KCC.

\section{Peer Counselling}

Training of volunteered students of Graduate School as Peer Counsellors as done for the undergraduate students. Peer counselling has been identified as one of the effective ways in supporting professional counselling at KNUST. Thus, the KCC trains about 100-200 students every year to support their colleague students. They are taken through the basics in counselling and they do a lot of referrals to the KCC for professional support. We therefore propose the training of IDL Students as Peer Counsellors to provide support for their colleagues and also make referrals to the KCC when needed. These Peer Counsellors would be supervised by the KCC.

3. Training of IDL staff (Coordinators) as Skilled Helpers

Training of volunteered staff (e.g. Graduate Coordinators in the various Departments) as Skilled Helpers. The KCC train some staff members of KNUST who volunteer as skilled helper to augment the provision of counselling services to students and staff of KNUST annually. They are taken through a Certification Programme to equip them with skills as para-professionals. The KCC could be tasked to train the coordinators of the various centres of IDL as skilled helpers to provide immediate counselling services to the students. Again, they can serve as facilitators to make presentation on counselling services offered by KNUST to its students during freshman orientation and matriculation. This would save cost since the staff of KCC would not have to travel long distances to the various centers to make presentations. The risk of travelling would also be averted. 


\section{Counsellor on Call}

Counsellor visiting the Graduate Students' Office at least once a week to attend to clients. Again, a Counsellor from the KNUST Counselling Center could be on call during weekends for IDL emergencies in the interim. The coordinators would put together issues that need professional assistance and inform the counsellor in-charge for his/her attention during the weekend.

In the long term, we recommend that the University would hire more Counsellors so that some could be designated to handle issues bothering students and staff of IDL.

\section{Involvement of KCC in special orientation and programmes of the Graduate Students of KNUST}

It is recommended that the leadership of Graduate Students Association of Ghana (GRASAG), KNUST branch could collaborate with the KCC to organize tailor made programmes for graduate students and to make presentation on special issues of importance at their orientation programmes.

\subsection{Expectation}

It is envisaged that if the recommendations above are considered, KNUST stands to accrue the following benefits:

- Identify and handle issues or challenges of graduate students at the onset before it get out of hand.

- Reduce stress and anxiety associated with their academic and psychosocial life.

- Above all, graduate students would be provided with services and skills for self-management to achieve their subjective wellbeing.

- Graduate and post graduate students will be equipped with skills such as good time management with regard to adjustment to studying and achieving a balance between social and academic activities which appear to play a major role in successful degree completion (Summers, B., \& Dolane I. M., 2014).

\section{References}

Amedahe, F. K. (2003): Notes on educational research. Cape Coast: Unpublished Collins, G. R. (2007): Christian counselling: A comprehensive guide (3 $3^{\text {rd }}$ ed.): Texas

Evans, T., Evans, B., \& Marsh, H. (n.d.). International Doctoral Conference Commissioned Paper: Australia. http://depts.washington.edu/eirgecon/papers/australia.doc20/8/2011 (http://depts.washington.edu/eirgecon/papers/australia.doc20/8/2011) [Google Scholar]

Fox, C. L., \& Butler, I. (2007). 'If you don't want to tell anyone else you can tell her' young people's views on school counselling. British Journal of Guidance \& Counselling, 35(1), 97-114. doi:10.1080/03069880601106831.

Ipaye, T. (2000). Guidance and counselling practice, Ife: University of Ife Press

KNUST (2020). Action Plan, Vision 2020-2024, University Press, Kumasi

Mark, P. (2012) Building bridges: higher degree student retention and counselling support, Journal of Higher Education Policy and Management, 34:2, 187-199, DOI: 10.1080/1360080X.2012.662743

Pitchforth, J., Beames, S., Thomas, A., Falk, M., Farr, C., Gasson, S., Thamrin, S.A., \& Mengersen, K. (2012). Factors Affecting Timely Completion of a PhD: A Complex Systems Approach. Journal of the Scholarship of Teaching and Learning, 12(4), 124-135.

Sarantakos, S. (1998): Social research (2nd ed.). Hong Kong: Macmillan Press Ltd.

Summers, B., \& Dolane I. M., (2014). "Factors That Influence MSc (Med) (Pharmacy) Completion Rates at the Medunsa Campus of the University of Limpopo, South Africa." African Journal of Health Professions Education 6(2):129-132. 